\title{
The impact of inpatient suicide on psychiatric nurses and their need for support
}

\author{
Chizuko Takahashi ${ }^{1 \dagger}$, Fuminori Chida ${ }^{2}$, Hikaru Nakamura ${ }^{2 \dagger}$, Hiroshi Akasaka ${ }^{3}$, Junko Yagi ${ }^{2}$, Atsuhiko Koeda $^{2}$, \\ Eri Takusari ${ }^{2}$, Kotaro Otsuka ${ }^{2 * \dagger}$, Akio Sakai ${ }^{2+}$
}

\begin{abstract}
Background: The nurses working in psychiatric hospitals and wards are prone to encounter completed suicides. The research was conducted to examine post-suicide stress in nurses and the availability of suicide-related mental health care services and education.

Methods: Experiences with inpatient suicide were investigated using an anonymous, self-reported questionnaire, which was, along with the Impact of Event Scale-Revised, administered to 531 psychiatric nurses.

Results: The rate of nurses who had encountered patient suicide was 55.0\%. The mean Impact of Event ScaleRevised (IES-R) score was 11.4. The proportion of respondents at a high risk ( $\geq 25$ on the 88-point IES-R score) for post-traumatic stress disorder (PTSD) was 13.7\%. However, only $15.8 \%$ of respondents indicated that they had access to post-suicide mental health care programmes. The survey also revealed a low rate of nurses who reported attending in-hospital seminars on suicide prevention or mental health care for nurses (26.4\% and $12.8 \%$, respectively).

Conclusions: These results indicated that nurses exposed to inpatient suicide suffer significant mental distress. However, the low availability of systematic post-suicide mental health care programmes for such nurses and the lack of suicide-related education initiatives and mental health care for nurses are problematic. The situation is likely related to the fact that there are no formal systems in place for identifying and evaluating the psychological effects of patient suicide in nurses and to the pressures stemming from the public perception of nurses as suppliers rather than recipients of health care.
\end{abstract}

\section{Background}

Psychiatric disorders have been identified as among the strongest risk factors for suicide $[1,2]$. Psychiatric inpatients thus constitute a high-risk group for suicide attempts. For these reasons, nurses working in psychiatric hospitals and psychiatric wards are more prone to encounter suicidal ideation in patients and attempted or completed suicides than nurses in other departments.

Previous studies have reported that patient suicide have a severe emotional impact in some psychiatrists and psychiatric trainees [3], and personal grief in therapists [4]. The completed suicide of a patient represents a critical event for a nurse who was in charge of or had

\footnotetext{
*Correspondence: kotaro29@df6.so-net.ne.jp

+ Contributed equally

2Department of Psychiatry, Iwate Medical University, 19-1 Uchimaru, Morioka, 020-8505 Japan

Full list of author information is available at the end of the article
}

some contact with the patient, and the nurse may blame him/herself and experience feelings of worthlessness associated with his/her inability to prevent the patient's death $[5,6]$. However, results from one study show that only $34 \%$ of 106 surveyed psychiatric hospitals throughout Japan provided mental health care programmes for their staff following patient suicide [7]. Current Japanese psychiatric care systems have been slow to adopt staff-oriented programmes on suicide and post-suicide care, partly due to persistent resistance and a distorted view of suicide on the part of psychiatric health care providers [8].

This study investigated the experiences of psychiatric nursing staff exposed to patient suicide, self-evaluation of post-suicide stress, and availability of suicide-related mental health care services and education. The purpose of this study was to investigate issues related to patient
C Biomed Central

(c) 2011 Takahashi et al; licensee BioMed Central Ltd. This is an Open Access article distributed under the terms of the Creative Commons Attribution License (http://creativecommons.org/licenses/by/2.0), which permits unrestricted use, distribution, and reproduction in any medium, provided the original work is properly cited. 
suicide in mental health nursing in the hopes of contributing to the mental health of nurses.

\section{Methods}

A survey questionnaire, together with the IES-R, was sent over a period from July 18, 2008 to August 1, 2008 to 562 psychiatric nurses working at eight psychiatric medical institutions (two general and six psychiatric hospitals) located in City A and its environs in the northern Tohoku region of Japan. The nurses surveyed worked in inpatient wards, outpatient clinics, day-care services, and other related facilities. All of the respondents had experience working in psychiatric inpatient wards.

The questionnaire was designed and prepared for this study based on suicide-related papers previously published in Japan [9-11], documents related to the Basic Law on Suicide Countermeasures (2006), survey items used in a survey conducted among the general public by the Cabinet Office (2007), and survey items used by Minami and colleagues [7]. We did not perform any pilot study in advance of the current questionnaire survey, determining it unnecessary, given that our survey consists of questions based on the aforementioned Law, the results of reliable studies, and other reliable information. All survey items were carefully assessed in advance by psychiatrists, public health nurses, and experts in ethics and statistics.

The questionnaire, which is printed on A4 paper and consists of eight pages including the cover page, is divided into the following four major sections: 'Your perception of suicide', 'Patient suicide', 'Current on-site support systems', and 'About yourself'. Each section has roughly ten subsections. In addition, each subsection contains roughly ten questions.

The questionnaire as a whole asked questions on (1) the experience of exposure to completed inpatient suicide, (2) the availability of mental health care services for affected nursing staff and the perceived need for post-event mental health care initiatives, and (3) on-site support systems. The final item (3) concerned the presence and scope of educational training conducted for the professional development of psychiatric nurses. More specifically, questions involved such matters as whether on-site training had been conducted in the preceding three years relating to stress-coping methods, suicide prevention measures, mental health care for nurses, risk management, etc., and whether the respondents ask questions or whether they have anyone to consult with when they encounter an unfamiliar problem at work. The purpose of asking this series of questions was to determine the level of opportunity available to them to develop a better understanding of suicide and suicide prevention, and how much training there is on suicide-related issues, such as psychiatric disorders and stress. In addition, nurses who witnessed a patient suicide attempt were asked about the situation at the time of the encounter, the degree of relationship with the patient, and related questions.

The IES-R sent with the questionnaire is a post-traumatic stress symptom scale. It is designed to measure, with its Intrusion, Hyperarousal, and Avoidance subscales, the three types of PTSD symptoms that are said to occur after traumatic experiences such as crime, disasters, and accidents. The validity and reliability of the scale have been demonstrated by others [12].

Sufficient care was taken to maintain confidentiality; individuals who completed the questionnaire remained completely anonymous. The questionnaire sheets were placed in envelopes and distributed to each respondent individually. The respondents themselves sealed their responses in the envelopes before submission. Consent to the survey was assumed on the part of respondents who opted to complete and return the form. This study was approved by the Iwate Medical University Ethics Committee.

Statistical analysis (chi-square) was performed using the IBM SPSS Statistics software package (Version 16J, SPSS Japan Inc., Tokyo, Japan).

\section{Results}

A total of 531 individuals (94.5\%) responded (Table 1). This high response rate was probably due to the prior explanations of the gist of this study and the requests for cooperation put in to the management of the medical institutions (directors of hospitals and managers of nursing departments) verbally and in writing.

The female/male ratio of the respondents was greater than 2:1. The overall average age was early forties; the mean age was higher for female respondents than male. The mean duration of psychiatric nursing experience was $11.8 \pm 1.0$ years out of $17.9 \pm 11.9$ years' professional nursing experience. About $60 \%(n=317)$ of the respondents were registered nurses, while some $30 \%(n=155)$ were licensed practical nurses. Nurses in Japan are classified as either "registered nurses", who have passed a national examination and are granted a license by the Minister of Health, Labour, and Welfare, or "licensed practical nurses", who are granted a license by the governor of one of the 47 prefectures to perform nursing services under the direction of registered nurses. Eleven and a half per cent $(n=61)$ of them held management-level positions (chief nurse or higher), and more than $70 \%(\mathrm{n}=391)$ engaged in general nursing services.

\section{Experience with completed inpatient suicide (Table 2)}

More than half of the respondents $(n=292)$ stated that they had experienced a case of completed suicide by an inpatient. Of those, $28.8 \%$ of the experiences $(n=84)$ 


\begin{tabular}{|c|c|c|c|c|c|c|c|c|c|}
\hline & & \multicolumn{2}{|c|}{$\begin{array}{c}\text { Total } \\
n=531\end{array}$} & \multicolumn{2}{|c|}{$\begin{array}{l}\text { Females } \\
\mathrm{n}=332\end{array}$} & \multicolumn{2}{|c|}{$\begin{array}{c}\text { Males } \\
n=153\end{array}$} & \multicolumn{2}{|c|}{$\begin{array}{l}\text { No/inappropriate answer } \\
\qquad n=46\end{array}$} \\
\hline & & $\mathrm{n}$ & $\%$ & $\mathrm{n}$ & $\%$ & $\mathrm{n}$ & $\%$ & $\mathbf{n}$ & $\%$ \\
\hline \multicolumn{2}{|c|}{ Mean age, $+/-$ SD } & 41.9 & \pm 12.3 & 43.6 & \pm 12.4 & 38.2 & \pm 11.1 & & \\
\hline & 20 to 29 years & 91 & 17.1 & 56 & 16.9 & 35 & 22.9 & 0 & 0.0 \\
\hline & 30 to 39 years & 99 & 18.6 & 50 & 15.1 & 49 & 32.0 & 0 & 0.0 \\
\hline \multirow[t]{4}{*}{ Age group } & 40 to 49 years & 135 & 25.4 & 97 & 29.2 & 38 & 24.8 & 0 & 0.0 \\
\hline & 50 to 59 years & 97 & 18.3 & 82 & 24.7 & 15 & 9.8 & 0 & 0.0 \\
\hline & 60 years or older & 36 & 6.8 & 29 & 8.7 & 7 & 4.6 & 0 & 0.0 \\
\hline & No/inappropriate answer & 73 & 13.7 & 18 & 5.4 & 9 & 5.9 & 46 & 100.0 \\
\hline \multicolumn{2}{|c|}{ Total years of nursing experience, $+/-$ SD } & 17.9 & \pm 11.9 & 19.8 & \pm 12.0 & 14.0 & \pm 10.8 & & \\
\hline & Maximum years & 55.0 & & 55.0 & & 47.0 & & & \\
\hline & Minimum years & 0.1 & & 0.1 & & 0.3 & & & \\
\hline & No/inappropriate answer & 65 & 12.2 & 14 & 4.2 & 5 & 3.3 & 46 & \\
\hline \multicolumn{2}{|c|}{ Total years as psychiatric nurse, +/- SD } & 11.8 & \pm 1.0 & 11.4 & \pm 9.0 & 12.6 & \pm 10.6 & & \\
\hline & Maximum years & 47.0 & & 36.3 & & 47.0 & & & \\
\hline & Minimum years & 0.1 & & 0.1 & & 0.2 & & & \\
\hline & No/inappropriate answer & 61 & 11.5 & 11 & 3.3 & 5 & 3.3 & 46 & \\
\hline & Registered nurse & 317 & 59.7 & 209 & 63.0 & 108 & 70.6 & 0 & 0.0 \\
\hline \multirow[t]{3}{*}{ Distinction } & Licensed practical nurse & 155 & 29.2 & 113 & 34.0 & 42 & 27.5 & 1 & 2.2 \\
\hline & No/inappropriate answer & 59 & 11.1 & 10 & 3.0 & 3 & 2.0 & 45 & 97.8 \\
\hline & Management: chief nurse or higher & 61 & 11.5 & 36 & 10.8 & 25 & 16.3 & 0 & 0.0 \\
\hline \multirow[t]{2}{*}{ Post } & Other & 391 & 73.6 & 273 & 82.2 & 117 & 76.5 & 0 & 0.0 \\
\hline & No/inappropriate answer & 79 & 14.9 & 23 & 6.9 & 11 & 7.2 & 46 & 100.0 \\
\hline
\end{tabular}

Description: Background factors of the subjects,i.e.,mean age,total years of nursing experience,total years of psychiatric nursing experience, distinction of nursing staff, ,post,experience of suicide someone close.

occurred comparatively recently, within one or two years. One-fourth of the nurses $(n=70)$ encountered suicides from midnight to early morning hours. More than half of the suicide attempts $(\mathrm{n}=162)$ occurred in the psychiatric ward. More than $60 \%$ of the nurses $(n=191)$ were not in physical proximity to the patient at the time of the suicide. The following situations were typical: the patient was given overnight home leave or permission to go on an outing, the nurse was off duty, or the nurse had yet to leaving home for work. However, more than $30 \%$ of the reported cases $(n=97)$ took place during working hours, and in several cases the nurse was involved in attempts to resuscitate the patient. Although only a small proportion of respondents $(\mathrm{n}=10)$ answered that they were the designated nurse in charge of the patient who completed suicide, more than $60 \%$ of the surveyed nurses $(n=187)$ indicated that they had at least some contact with the patient.

Although not shown in the table, the number of nurses who encountered patient suicide during their working hours and were involved in the transport of the deceased or similar procedures was 39 (13.4\%).

\section{IES-R scale evaluation}

The severity of PTSD symptoms was measured using the IES-R scale for 292 nurses who had been exposed to inpatient suicide events to evaluate the psychological impact of the incident (Table 3). The PTSD high-risk group was defined as those scoring 25 or higher on the 88-point IES-R scale, based on the screening results reported by Asukai [9]. The number of PTSD high-risk individuals was 40 (13.7\%).

Each question was rated on a five-point scale. Particularly strong responses were noted for: two intrusionrelated symptoms, i.e. \#1 ("Any reminder brings back feelings about it") and \# 6; three avoidance-related symptoms, i.e. \#5 and \#11 ("I tried not to think about it") and \#12); and one hypervigilance-related symptom, namely \#21 (I felt watchful or on-guard).

\section{Availability of mental health care programmes and the perceived need for them}

About $80 \%(n=234)$ of the nurses who encountered inpatient suicide responded that no mental health care programmes were implemented for nursing staff following the suicide (Table 4). Our questionnaire included statements on whether or not their hospitals provided occasions for suicide-related discussion or a case study review after the event. Those questions were adopted by revision and supplementation of the survey items adopted by Minami [7]. 
Table 2 Rates of nurses who encountered completed patient suicide and details of the encounter

\begin{tabular}{|c|c|c|}
\hline & & No.of respondents(\%) \\
\hline Did you encounter an inpatient suicide? & Yes & $292(55.0)$ \\
\hline \multirow[t]{2}{*}{$(n=531)$} & No & 209 (39.4) \\
\hline & No/inapporopriate answer & $30(5.6)$ \\
\hline How many years have passed since the encounter? & 20 or more years & $15(5.1)$ \\
\hline \multirow[t]{5}{*}{$(n=292)$} & 10 to 20 years & $55(18.8)$ \\
\hline & 5 to 10 years & $29(9.9)$ \\
\hline & 3 to 5 years & $51(17.5)$ \\
\hline & 1 to 2 years & $84(28.8)$ \\
\hline & No/inapporopriate answer & $58(19.9)$ \\
\hline In which time period? & 0 a.m. to 7 a.m. & $70(24.0)$ \\
\hline \multirow[t]{3}{*}{$(n=292)$} & 8 a.m. to 4 p.m. & $40(13.7)$ \\
\hline & 5 p.m. to 11 p.m. & $45(15.4)$ \\
\hline & No/inapporopriate answer & $137(46.9)$ \\
\hline Where did it take place? & In the psychiatric ward & $162(55.5)$ \\
\hline \multirow[t]{3}{*}{$(n=292)$} & Outside the hospital (in the patient's home or during an outing) & $102(34.9)$ \\
\hline & Other & $14(4.8)$ \\
\hline & No/inapporopriate answer & $14(4.8)$ \\
\hline When the event happened,you were: & Off from work & $75(25.7)$ \\
\hline \multirow[t]{5}{*}{$(n=292)$} & Prior to going off duty & $33(11.3)$ \\
\hline & On duty & $58(19.9)$ \\
\hline & On duty and involved in post-event treatment & $39(13.4)$ \\
\hline & Out of hospital & $83(28.4)$ \\
\hline & No/inapporopriate answer & $4(1.4)$ \\
\hline How closely were you involved with the patient? & No involved & $26(8.9)$ \\
\hline \multirow[t]{4}{*}{$(n=292)$} & Little involvement & $64(21.9)$ \\
\hline & Not charged but involved & $187(64.0)$ \\
\hline & Charged & $10(3.4)$ \\
\hline & No/inapporopriate answer & $5(1.7)$ \\
\hline
\end{tabular}

Description: Data of the subjects,i.e., the fact that nurses encountered patients' suicide, years since the encounter, time and place of the encounter, situation when the encounter took place, involvement and relation of nurses to suicidei.

Most of the responses favoured implementing stafforiented mental health care programmes following a suicide, and recognized the need for developing a more compassionate attitude toward suicide, as well as the need for sharing information on the course of events leading up to the suicide (Table 5).

A significant difference was observed in the amount of knowledge and awareness regarding suicide and in the perceived need for mental health care for staff members between nurses in managerial positions and other nurses. However, no significant difference was observed between licensed practical nurses and registered nurses.

\section{On-site support systems}

When respondents were asked about the topics of onsite seminars held in the previous three years, more than $50 \%$ of the answers reported seminars or workshops on 'psychiatric diseases' $(60.3 \%, \mathrm{n}=320)$ and 'risk management' ( $54.4 \%, \mathrm{n}=289)$. However, less than $20 \%$ indicated 'group approaches' $(11.1 \%, \mathrm{n}=59)$, 'mental health care for nursing staff' $(12.8 \%, \mathrm{n}=68)$, and 'stresscoping methods' $(16.9 \%, \mathrm{n}=90)$. Rates of those who had attended a 'suicide and suicide prevention measures' seminar were higher, with a response of $26.4 \%(n=140)$ (Table 6).

\section{Discussion}

Although this study focused only on cases of completed suicide, more than half $(55.0 \%)$ of respondents had had experience with patient suicide. Previous studies on psychiatric nurses exposed to patient suicide reported rates of 58.3\% [10] and 32.4\% [11]. Another study indicated that $66 \%$ of psychiatric hospitals or hospitals with psychiatric wards (the total number is 106) reported suicidal events [7]. These previous reports, however, include unsuccessful suicide attempts. In this regard, a very high rate was obtained from the current study. In Japan, the annual number of suicides has exceeded thirty thousand for 12 consecutive years, and the suicide rate is exceptionally high compared to the figures in other advanced 


\begin{tabular}{|c|c|c|c|c|c|c|c|c|c|c|c|c|c|c|}
\hline & \multicolumn{2}{|c|}{ Not at all } & \multicolumn{2}{|c|}{ A little bit } & \multicolumn{2}{|c|}{ Moderately } & \multicolumn{2}{|c|}{ Quite a bit } & \multicolumn{2}{|c|}{ Extremely } & \multicolumn{2}{|c|}{$\begin{array}{c}\text { No/inappropriate } \\
\text { answer }\end{array}$} & \multicolumn{2}{|c|}{ Total } \\
\hline & $\mathbf{n}$ & $\%$ & $\mathbf{n}$ & $\%$ & $\mathbf{n}$ & $\%$ & $\mathbf{n}$ & $\%$ & $\mathbf{n}$ & $\%$ & $\mathrm{n}$ & $\%$ & $\mathrm{n}$ & $\%$ \\
\hline Any reminder brought back feelings about it & 63 & 21.6 & 117 & 40.1 & 63 & 21.6 & 25 & 8.6 & 15 & 5.1 & 9 & 3.1 & 292 & 100 \\
\hline I had trouble staying asleep & 206 & 70.5 & 37 & 12.7 & 28 & 9.6 & 8 & 2.7 & 1 & 0.3 & 12 & 4.1 & 292 & 100 \\
\hline Other things kept making me think about it & 189 & 64.7 & 58 & 19.9 & 24 & 8.2 & 6 & 2.1 & 6 & 2.1 & 9 & 3.1 & 292 & 100 \\
\hline I felt irritable and angry & 234 & 80.1 & 38 & 13.0 & 7 & 2.4 & 4 & 1.4 & 0 & 0.0 & 9 & 3.1 & 292 & 100 \\
\hline $\begin{array}{l}\text { I avoided letting myself get upset when I thought } \\
\text { about it or was reminded of it }\end{array}$ & 145 & 49.7 & 91 & 31.2 & 24 & 8.2 & 17 & 5.8 & 5 & 1.7 & 10 & 3.4 & 292 & 100 \\
\hline I thought about it when I didn't mean to & 133 & 45.5 & 100 & 34.2 & 31 & 10.6 & 14 & 4.8 & 3 & 1.0 & 11 & 3.8 & 292 & 100 \\
\hline I felt as if it hadn't happened or wasn't real & 199 & 68.2 & 46 & 15.8 & 21 & 7.2 & 5 & 1.7 & 1 & 0.3 & 20 & 6.8 & 292 & 100 \\
\hline I stayed away from reminders about it & 197 & 67.5 & 53 & 18.2 & 15 & 5.1 & 7 & 2.4 & 3 & 1.0 & 17 & 5.8 & 292 & 100 \\
\hline Pictures about it popped into my mind & 193 & 66.1 & 59 & 20.2 & 14 & 4.8 & 8 & 2.7 & 3 & 1.0 & 15 & 5.1 & 292 & 100 \\
\hline I was jumpy and easily startled & 172 & 58.9 & 63 & 21.6 & 24 & 8.2 & 11 & 3.8 & 9 & 3.1 & 13 & 4.5 & 292 & 100 \\
\hline I tried not to think about it & 152 & 52.1 & 67 & 22.9 & 34 & 11.6 & 18 & 6.2 & 7 & 2.4 & 14 & 4.8 & 292 & 100 \\
\hline $\begin{array}{l}\text { I was aware that I still had a lot of feelings about it, } \\
\text { but I didn't deal with them }\end{array}$ & 165 & 56.5 & 62 & 21.2 & 26 & 8.9 & 17 & 5.8 & 6 & 2.1 & 16 & 5.5 & 292 & 100 \\
\hline My feelings about it were kind of numb & 162 & 55.5 & 70 & 24.0 & 35 & 12.0 & 6 & 2.1 & 2 & 0.7 & 17 & 5.8 & 292 & 100 \\
\hline $\begin{array}{l}\text { I found myself acting or feeling as though I was } \\
\text { back at that time }\end{array}$ & 214 & 73.3 & 42 & 14.4 & 17 & 5.8 & 4 & 1.4 & 1 & 0.3 & 14 & 4.8 & 292 & 100 \\
\hline I had trouble falling asieep & 212 & 72.6 & 38 & 13.0 & 14 & 4.8 & 10 & 3.4 & 4 & 1.4 & 14 & 4.8 & 292 & 100 \\
\hline I had waves of strong feelings about it & 192 & 65.8 & 53 & 18.2 & 22 & 7.5 & 9 & 3.1 & 5 & 1.7 & 11 & 3.8 & 292 & 100 \\
\hline I tried to remove it from my memory & 201 & 68.8 & 42 & 14.4 & 21 & 7.2 & 9 & 3.1 & 4 & 1.4 & 15 & 5.1 & 292 & 100 \\
\hline I had trouble concentrating & 226 & 77.4 & 40 & 13.7 & 9 & 3.1 & 3 & 1.0 & 1 & 0.3 & 13 & 4.5 & 292 & 100 \\
\hline $\begin{array}{l}\text { Reminders of it caused me to have physical } \\
\text { reactions,such as sweating,trouble breathing,nausea, } \\
\text { or a pounding heart }\end{array}$ & 227 & 77.7 & 38 & 13.0 & 12 & 4.1 & 4 & 1.4 & 0 & 0.0 & 11 & 3.8 & 292 & 100 \\
\hline I had dreams about it & 246 & 84.2 & 28 & 9.6 & 4 & 1.4 & 1 & 0.3 & 0 & 0.0 & 13 & 4.5 & 292 & 100 \\
\hline I felt watchful or on-guard & 112 & 38.4 & 92 & 31.5 & 41 & 14.0 & 20 & 6.8 & 14 & 4.8 & 13 & 4.5 & 292 & 100 \\
\hline I tried not to talk about it & 187 & 64.0 & 54 & 18.5 & 22 & 7.5 & 11 & 3.8 & 5 & 1.7 & 13 & 4.5 & 292 & 100 \\
\hline
\end{tabular}

Description: Scores of IES-R (Impact of Event Scale-Revised [Weiss \& Marmar, 1997]).

countries. The suicide rate in the prefecture, where respondents to the current questionnaire survey are located, is one of the highest in Japan [13]. The present survey results may reflect this regional tendency.

Table 4 Post-suicide follow-up care programs for nurses

\begin{tabular}{llr}
\hline & & No.of respondents(\%) \\
\hline $\begin{array}{l}\text { Mental health care } \\
\text { program }\end{array}$ & Implemented & $46(15.8)$ \\
& Not implemented & \\
& No/inapporopriate & $234(80.1)$ \\
& answer & $12(4.1)$ \\
\hline $\begin{array}{l}\text { Case study session } \\
\text { was: }\end{array}$ & Held at safety & $23(7.9)$ \\
$(\mathrm{n}=292)$ & committee & \\
& Held at ward/unit & $68(23.3)$ \\
& meeting & \\
& Held by limited staff & $75(25.7)$ \\
& Other & $24(8.2)$ \\
& Not held & $83(28.4)$ \\
& No/inapporopriate & $19(6.5)$ \\
& answer & \\
\hline
\end{tabular}

Description: Whether mental health care programs and case study sessions were available for nurses who encountered patients' suicide.
More than half of the nurses who encountered suicide by patients stated that they had had at least some contact with them. Patient suicide is an extremely serious incident for medical professionals. The few studies published suggest that it is quite common for residents to encounter patient suicide during their training and that they undergo significant levels of psychological stress [14]. Sudak suggested that the feelings experienced by residents and clinicians following the suicide by patient are quantitatively smaller than in the case of suicide by a family member but are similar to them qualitatively [15].

Despite some difficulties in comparison arising from the use of different methods and other factors, similar IES-R scores have been reported for significantly disastrous events. In a study evaluating general traumatic events (e.g., physical abuse, sexual harassment, obsessive relational intrusion, becoming the target of unwanted romantic attention, and patient suicide) among 124 psychiatric nurses, the mean IES-R score was 13.4, and 18 nurses (14.5\%) were classified in the high-risk group [16]. The mean IES- $R$ subscale scores (avoidance, 


\begin{tabular}{|c|c|c|c|c|c|c|c|c|c|c|c|c|}
\hline & \multicolumn{2}{|c|}{$\begin{array}{l}\text { Not at } \\
\text { all }\end{array}$} & \multicolumn{2}{|c|}{$\begin{array}{c}\text { Don't } \\
\text { think } \\
\text { so }\end{array}$} & \multicolumn{2}{|c|}{ Think so } & \multicolumn{2}{|c|}{$\begin{array}{l}\text { Strongly } \\
\text { think so }\end{array}$} & \multicolumn{2}{|c|}{$\begin{array}{c}\mathrm{No} / \\
\text { inappropriate } \\
\text { answer }\end{array}$} & \multicolumn{2}{|c|}{ Total } \\
\hline & n & $\%$ & $\mathbf{n}$ & $\%$ & n & $\%$ & n & $\%$ & $\mathbf{n}$ & $\%$ & $\mathbf{n}$ & $\%$ \\
\hline $\begin{array}{l}\text { Mental health care programs following patient suicide are necessary for } \\
\text { medical staff. }\end{array}$ & 1 & 0.2 & 22 & 4.1 & 153 & 28.8 & 283 & 53.3 & 72 & 13.6 & 531 & 100.0 \\
\hline Mental health issues cannot be solved by oneself. & 4 & 0.8 & 57 & 10.7 & 315 & 59.3 & 122 & 23.0 & 33 & 6.2 & 531 & 100.0 \\
\hline Inaction worsens mental health issues. & 7 & 1.3 & 60 & 11.3 & 323 & 60.8 & 104 & 19.6 & 37 & 7.0 & 531 & 100.0 \\
\hline Inappropriate mental health care may cause staff to resign. & 9 & 1.7 & 90 & 16.9 & 259 & 48.8 & 138 & 26.0 & 35 & 6.6 & 531 & 100.0 \\
\hline Mental health care programs help to prevent suicide. & 12 & 2.3 & 97 & 18.3 & 290 & 54.6 & 94 & 17.7 & 38 & 7.2 & 531 & 100.0 \\
\hline Proper knowledge about suicide should be needed. & 2 & 0.4 & 18 & 3.4 & 276 & 52.0 & 201 & 37.9 & 34 & 6.4 & 531 & 100.0 \\
\hline Staff should share information on the course of events that led to suicide. & 1 & 0.2 & 25 & 4.7 & 268 & 50.5 & 204 & 38.4 & 33 & 6.2 & 531 & 100.0 \\
\hline Mental health care programs should cover all medical staff. & 5 & 0.9 & 43 & 8.1 & 278 & 52.4 & 169 & 31.8 & 36 & 6.8 & 531 & 100.0 \\
\hline Mental health care programs will reduce staff's psychological burdens. & 5 & 0.9 & 61 & 11.5 & 305 & 57.4 & 124 & 23.4 & 36 & 6.8 & 531 & 100.0 \\
\hline $\begin{array}{l}\text { Discussion about the cause of suicide is useful for mental health } \\
\text { management. }\end{array}$ & 6 & 1.1 & 81 & 15.3 & 304 & 57.3 & 103 & 19.4 & 37 & 7.0 & 531 & 100.0 \\
\hline $\begin{array}{l}\text { Mental health care programs involving external professionals should be } \\
\text { considered. }\end{array}$ & 7 & 1.3 & 99 & 18.6 & 290 & 54.6 & 98 & 18.5 & 37 & 7.0 & 531 & 100.0 \\
\hline
\end{tabular}

Description: Whether the nurses recognized the need for mental health programs.

intrusion, hypervigilance) obtained in this study were compared with those in a preceding study [16].

In this study, most of the nurses indicated the desire for mental health care programmes for health care workers who have experienced a shocking event on the ward. This indicates that most psychiatric nurses are aware of the need for staff-oriented mental health care services. In actual terms, however, only $15.8 \%$ of the respondents reported the availability of mental health care programmes for health care workers following a suicide event. In Japanese medical practice, it is often the case that when a patient completes suicide, the situation is not conducive to the provision of psychological assistance for nurses in charge of the patient [17]. The results obtained in this study reflect in part current style of Japanese psychiatric practice management, as shown above.

Nonetheless, inadequacies at facilities overseas have been reported as well. For example, Mangurian and colleagues reported that, when they encountered patient suicide during their own residencies, they found that emotional support and support by medical institutions were lacking [18].

The patient suicide-related issues considered here derive from both the circumstances of the profession and nurses' perception of their own social role. Expressing bitter feelings is often considered by nurses and other medical professionals to be giving in to one's weaknesses and exposing one's helplessness to others. Nurses fear that disclosure of their weaknesses would damage their professional reputation, and this fear could be one of the reasons for not speaking up.

Consequently, nurses who have lost a patient due to suicide are troubled by the thought that they may be responsible for the death. This sense of guilt and selfcondemnation can result in depression and other PTSD symptoms and can affect professional identity and nursing skills and duties [6]. In addition, other nurses may develop a fear of going through a similar event again [19], which can lead to a dysfunctional medical care system.

Table 6 Subjects of on-site seminars held in the previous three years

\begin{tabular}{|c|c|c|c|c|c|c|c|c|}
\hline & \multicolumn{2}{|c|}{ No } & \multicolumn{2}{|c|}{ Yes } & \multicolumn{2}{|c|}{ No/inappropriate answer } & \multicolumn{2}{|c|}{ Total } \\
\hline & $\mathbf{n}$ & $\%$ & $\mathrm{n}$ & $\%$ & n & $\%$ & $\mathrm{n}$ & $\%$ \\
\hline Stress-coping methods & 345 & 65.0 & 90 & 16.9 & 96 & 18.1 & 531 & 100.0 \\
\hline Suicide and suicide prevention measures & 301 & 56.7 & 140 & 26.4 & 90 & 16.9 & 531 & 100.0 \\
\hline Psychiatric diseases & 139 & 26.2 & 320 & 60.3 & 72 & 13.6 & 531 & 100.0 \\
\hline Risk management & 161 & 30.3 & 289 & 54.4 & 81 & 15.3 & 531 & 100.0 \\
\hline Mental health care for nursing staff & 367 & 69.1 & 68 & 12.8 & 96 & 18.1 & 531 & 100.0 \\
\hline Skill upgrade and career advancement & 258 & 48.6 & 171 & 32.2 & 102 & 19.2 & 531 & 100.0 \\
\hline Cooperation with other professions & 289 & 54.4 & 145 & 27.3 & 97 & 18.3 & 531 & 100.0 \\
\hline Group approaches & 367 & 69.1 & 59 & 11.1 & 105 & 19.8 & 531 & 100.0 \\
\hline
\end{tabular}

Description: Variety of themes of on-site seminars for nurses. 
For these reasons, the timely implementation of appropriate mental health care programmes for nursing staff who have been through a patient suicide is a significant part of creating an effective medical care environment. Providing staff-oriented post-suicide mental health care programmes falls under the category of postvention activities. Postvention activities should enable verbal expression of the emotional shock of the bereaved. They also serve to liberate staff from the vicious circle of the depression that may result from the mistaken belief that the affliction is their own and no one else's. Moreover, they help staff members to unite through mutual support [5]. Group meetings can help nurses realize 'the universality of grief and reduce selfblame and excess responsibility' [20]. The daily practice of examining and sharing one's feelings paves the way for sharing deep emotional feelings associated with a patient's suicide [21]. This is not an issue exclusively for nurses. Sudak points out the importance of sharing opinions on suicide and freely discussing concerns with other residents [22]. In addition, Balon discusses the significance of the impact of patient suicide, looking back at an experience which he himself had during his residency, and asserts the usefulness of psychological autopsies shared with others for metal health care [23].

Among other interventions, nurses need suicide prevention education. As revealed by the present study, however, only a very low proportion of medical institutions provide on-site suicide-related seminars. Suiciderelated issues may be dealt with at seminars on risk management, which were held frequently according to our results. Risk management approaches can be applied to intervention and the prevention of inpatient suicide. Patients' risk factors for suicide are evaluated from information collected from admissions, and therapeutic and nursing plans are developed based on the results of the evaluation. Implementation of these plans helps identify subtle changes in behaviour. Such systems involve patients, their families, nurses, physicians, and other health care workers in the risk management programmes for suicide prevention [6].

Practical examples of suicide prevention education for medical and nursing students and nurses have been reported $[24,25]$. However, a majority of these programmes have been tailored to those engaged in prevention; relatively few programmes have provided information and support based on the assumption that the attendees might be affected by a patient's suicide. Suicide prevention education is invaluable. Nurses should be aware that they may be forced to deal with the suicide of patients or persons close to them.

This study revealed that in the medical institutions targeted for the survey, there is a lack of awareness of the impact of completed patient suicide in nurses, and that the need to educate nurses on issues related to suicide has not gained wide recognition. These conclusions are expected to apply to many different regions throughout Japan. Accordingly, we hope that this study will provide grounds for improving the present situation.

\section{Limitations}

We must be very careful about generalizing our findings to any nurse whose patient completes suicide, for the evidence as provided here comes from Japanese settings. Moreover, this study focused on psychiatric nurses in urban areas; nurses in other geographical areas and other medical professions were not addressed.

Though the questionnaire used in this study was based on the extant literature, including suicide-related papers, documents related to the Basic Law on Suicide Countermeasures and others, its validity and reliability has not yet been tested. A pilot study is therefore necessary if the questionnaire is to be put to use in the future.

It is generally reported that female nurses are at a higher risk for PTSD and related conditions than male nurses. However, gender differences in IES-R scores were not taken into consideration in this study.

\section{Conclusions}

The current study revealed that more than half of respondents (nurses) had experienced a patient's completed suicide. The IES-R score obtained for these nurses suggest that inpatient suicide was a significantly distressing event. However, though most of these nurses were aware of the need for staff-oriented mental health care services, systematic post-suicide mental health care programmes for nurses are rarely available. Moreover, initiatives for education on issues related to suicide and mental health care are lacking. Hence, improvement in support systems is needed to provide effective mental health care for nurses so that they can work more effective at primary prevention.

This study may be useful in providing grounds to improve the present situation by highlighting the significance of the impact of completed patient suicide on nurses, and the lack of mental health care and the illprepared educational system regarding issues related to patient suicide.

\section{Author details \\ 'Social Support Center Morioka, JT Honcho Bldg. 3F, 1-9-14 Honcho-Dori, Morioka, 020-0015 Japan. ${ }^{2}$ Department of Psychiatry, Iwate Medical University, 19-1 Uchimaru, Morioka, 020-8505 Japan. ${ }^{3}$ Hospital Management Section of Iwate Medical University Hospital, 19-1 Uchimaru, Morioka, 020- 8505 Japan.}

\section{Authors' contributions}

$C T$ and FC conceived of the study and participated in its design and coordination. $\mathrm{KO}$ and $\mathrm{AS}$ helped to draft the manuscript. HN performed the 
statistical analysis. HA, JY, AK and ET have made contributions to acquisition and analysis of data. All authors read and approved the final manuscript.

\section{Competing interests}

The authors declare that they have no competing interests.

Received: 17 June 2010 Accepted: 8 March 2011

Published: 8 March 2011

\section{References}

1. Takahashi Y: Suicide Postvention Tokyo, Japan: Igaku-shoin; 2004

2. Arsenault-Lapierre G, Kim C, Turecki G: Psychiatric Diagnoses in 3275 Suicides: A Meta-analysis. BMC Psychiatry 2004, 4:37

3. Ruskin R, Sakinofsky I, Bagby RM, Dickens S, Sousa G: Impact of Patient Suicide on Psychiatrists and Psychiatric Trainees. Academic Psychiatry 2004, 28:104-110.

4. Valente SM: Psychotherapist Reactions to the Suicide of a Patient. American Journal of Orthopsychiatry 1994, 64(4):614-621.

5. Shimozono S: How Should Nurses Overcome Patients' Unexpected Suicide? Expert Nurse 2003, 19(10):14-17.

6. Fukuyama N: Role of Nurses in Suicide Prevention. Kokoro no Kagaku (Human Mind) 2004, 51-55.

7. Minami Y: Investigation of Medical Safety Management in the Department of Psychiatry Part 1: Questionnaire on Suicide in Hospitals. Patient Safety Promotion Journal 2006, 13:64-69.

8. Takeshima T, Higuchi T, Takahashi Y, Watanabe N: Suicide Problem: LongTerm Measures. Japanese Society of Social Psychiatry 2007, 15:224-241.

9. Asukai N, Kato H, Kawamura N, Kim Y, Yamamoto K, Kishimoto J, Miyake Y, Nishizono-Maher A: Reliability and validity of the Japanese-language version of the impact of event scale-revised (IES-R-J). Four studies of different traumatic events. Journal of Nervous and Mental Disease 2002, 190:175-182.

10. Itoh O: Suicide Incidents Encountered by Clinical Psychiatric Nurses (Part 2). Suicide Prevention and Crisis Intervention 2006, 27(1):64-70.

11. Itoh O: Suicide Cases Encountered by Clinical Psychiatric Nurses Research and Study for Participants in the Study Meeting for Registered Nurses for Psychiatric Emergency Units and Acute Patients. Suicide Prevention and Crisis Intervention 2005, 26(1):32-39.

12. Weiss DS, Marmar CR: The impact of event scale-revised. In Assessing psychological trauma and PTSD. Edited by: Wilson JP, Keane TM. New York, US; The Guilford Press; 1997:399-411.

13. Statistics and Information Department: Vital statistics. Minister's Secretariat, Ministry of Health, Labour and Welfare.

14. Fang F, Kemp J, Jawandha A, Juros J, Long L, Nanayakkara S, Stepansky C, Thompson B, Anzia J: Encountering Patient Suicide: A Resident's Experience. Academic Psychiatry 2007, 31:340-344.

15. Sudak H: Encountering Patient Suicide: The Role of Survivors. Academic Psychiatry 2007, 31:333-335.

16. Ooka Y, Maeda M, Tanaka M, Takamatsu M, Yajima J, Oe M, Kanehara S, Tsujimaru S: Traumatic Responses of Psychiatric Nurses in the Work Place. Seishin Igaku (Clinical Psychiatry) 2007, 49(2):143-153.

17. Takahashi Y: Suicide Risk Management Health Care Professionals Should Know. 2 edition. Tokyo, Japan; Igaku-shoin; 2006.

18. Mangurian C, Harre E, Reliford A, Booty A, Cournos F: Improving Support of Residents After a Patient Suicide: A Residency Case Study. Academic Psychiatry 2009, 33:278-281.

19. Takei A: Emotion and Nursing: Implication of the Profession of Human Care Tokyo, Japan; Igaku-shoin; 2001.

20. Valente SM, Saunders JM: Nurses' Grief Reactions to a Patient's Suicide. Perspectives in Psychiatric Care 2002, 38:5-14.

21. Aoto Y: Loneliness and Mental Trauma in Nurses Should Be Cared for by Others. Psychiatric Mental Health Nursing 2001, 28-30.

22. Sudak D, Roy A, Sudak H, Lipschitz A, Maltsberger J, Hendin H: Deficiencies in Suicide Training in Primary Care Specialties: A Survey of Training Directors. Academic Psychiatry 2007, 31:345-349.

23. Balon R: Encountering Patient Suicide: The Need for Guidelines. Academic Psychiatry 2007, 31:336-337.

24. Kawanishi C, Suda A, Sato R, Yamada T, Kato D, Furuno T, Hirayasu Y, Goto E: Suicide Prevention Education for Medical Student (I) Need for Gatekeeper Education in the Faculty of Medicine. Abstracts of the 32nd Annual Meeting of the Japanese Association for Suicide Prevention 2008, 61.
25. Sazaki K, Miki A, Nakagami M: Suicide Prevention and Suicide Aftercare Designed by Nursing Students - Questionnaire Survey after One Month of Education. The 36th Proceedings of Japan Society of Nursing: Nursing Education 2005, 215-217.

\section{Pre-publication history}

The pre-publication history for this paper can be accessed here: http://www.biomedcentral.com/1471-244X/11/38/prepub

doi:10.1186/1471-244X-11-38

Cite this article as: Takahashi et al: The impact of inpatient suicide on psychiatric nurses and their need for support. BMC Psychiatry 2011 11:38.

\section{Submit your next manuscript to BioMed Central and take full advantage of:}

- Convenient online submission

- Thorough peer review

- No space constraints or color figure charges

- Immediate publication on acceptance

- Inclusion in PubMed, CAS, Scopus and Google Scholar

- Research which is freely available for redistribution

Submit your manuscript at www.biomedcentral.com/submit
Biomed Central 